\title{
COMPARATIVE STUDY OF PREVALENCE OF H. PYLORI IN PATIENTS WITH FUNCTIONAL DYSPEPSIA IN ALCOHOLICS AND NON-ALCOHOLICS
}

\author{
Bala Vignesh $R^{1}$, Kannan $R^{2}$, Manoj Karthik ${ }^{3}$
}

${ }_{1}^{1}$ Final Year Postgraduate Student, Department of General Surgery, Mahatma Gandhi Medical College and Research Institute.

${ }^{2}$ Associate Professor, Department of General Surgery, Mahatma Gandhi Medical College and Research Institute.

${ }^{3}$ Associate Professor, Department of General Surgery, Mahatma Gandhi Medical College and Research Institute.

ABSTRACT
BACKGROUND
Helicobacter pylori and Alcohol use are important factors among the numerous factors associated with Functional Dyspepsia. The
prevalence of functional dyspepsia and alcoholism is higher in India. This cross-sectional study was taken up to determine the
association between Helicobacter pylori and Alcohol use among Functional Dyspepsia patients.

\section{MATERIALS AND METHODS}

Functional Dyspepsia symptoms were identified using Rome III BI criteria. Four gastric mucosal biopsies were taken from the antrum by endoscopy. Two of them were tested for H. pylori in the urease broth by the Rapid Urease Test (RUT) and rest 2 specimens were sent for histopathological examinations. Either the RUT biochemical test or the HPE test was considered positive for H. Pylori. Alcoholism and the severity assessed by DSM-questionnaire.

\section{RESULTS}

Seventy functional dyspepsia patients were included in this study and of them 35 were alcoholics and 35 were non-alcoholics. The prevalence of $\mathrm{H}$. pylori in FD cases was significantly higher in non-alcoholics (82\%) compared to alcoholics (28\%) and this difference was statistically significant ( $\mathrm{p}$ value $<0.05$ ). On comparing the quantity of alcohol consumed, H. pylori was more prevalent (58\%) in people who consume 91 to 160 gms of alcohol. This is higher in comparison with people who consume less alcohol in the range of 31 to 90 gms $(13 \%)$. This difference is statistically significant ( $<<0.001)$.

\section{CONCLUSION}

Alcoholism is found to be a protective factor against $\mathrm{H}$. pylori infection among functional dyspepsia patients.

\section{KEYWORDS}

H. pylori, Functional Dyspepsia, Alcoholics, Non-Alcoholics.

HOW TO CITE THIS ARTICLE: Vignesh BR, Kannan R, Karthik M. Comparative study of prevalence of H. pylori in patients with functional dyspepsia in alcoholics and non-alcoholics. J. Evolution Med. Dent. Sci. 2017;6(40):3185-3188, D0I: $10.14260 /$ Jemds/2017/688

\section{BACKGROUND}

Dyspepsia in Greek means indigestion. Functional Dyspepsia (FD) means dyspepsia without any organic cause.(1) FD is widely prevalent in Asia compared to Western countries because of the food habits, culture, environmental and social factors.(2) Exact cause of FD is still a mystery under evaluation. Infective factors play a major role. Of them, $\mathrm{H}$. pylori prevalence is of the top most priority followed by postinfection with acute salmonella gastroenteritis.(3) Psychosocial factors like Stress, Anxiety and Depression also play a significant role.(4)

The Helicobacter pylori is a flagellated, motile, gram negative bacilli and its size is 2.4 to 4.0 micrometre long and $0.5-1.0 \mu \mathrm{m}$ wide. It colonises the gastric mucosa, especially the antrum.(5) It creates an alkaline environment for its survival by its virulence factors namely vacuolating cytotoxin (Vac A).(6) Of the host factors, ABO Lewis antigen has some association with $\mathrm{H}$. pylori infectivity.

Financial or Other, Competing Interest: None.

Submission 12-04-2017, Peer Review 07-05-2017,

Acceptance 12-05-2017, Published 18-05-2017.

Corresponding Author:

Bala Vignesh $R$

Om Sakthi Hospital, \#4 Sengodipuram,

Dharmapuri-636701, Tamilnadu.

E-mail: balvic7790@gmail.com

DOI: $10.14260 /$ jemds $/ 2017 / 688$

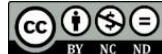

Most epidemiologic studies done for determining the $\mathrm{H}$. pylori prevalence have shown that in the developing countries it is $70 \%$ as compared to $40 \%$ in developed countries.(7) Alcoholism in India is on the rising horizon, probably due to westernising culture or as a stress relieving measure. The heartrending part is the influence of alcohol on the rural masses, who spoil their physical and mental health. The overall observation and expectation is that, because the symptoms of FD increases with increasing severity of alcoholism the H. pylori prevalence also should show the same relationship. There are not many studies available to reveal the association between $\mathrm{H}$. pylori, Alcoholics and FD. So the present study was done to determine the association of $\mathrm{H}$. pylori infection among alcoholics and non-alcoholics presenting with functional dyspepsia.

\section{MATERIALS AND METHODS}

This comparative study was conducted among 70 patients with functional Dyspepsia symptoms who satisfied Rome III BI criteria. The severity of FD symptoms was graded with Modified Glasgow Dyspepsia Severity (MGDSS) questionnaire. Patients with FD were subjected to USG abdomen to rule out Gall bladder and Pancreatic pathologies. Then they were subjected to upper GI endoscopy. Four gastric mucosal biopsies were taken from the antrum. Two of them were tested for $\mathrm{H}$. pylori in the urease broth by the Rapid Urease Test (RUT). Rapid urease test has a sensitivity and specificity of $95 \% .{ }^{(8)}$ 
The colour change from yellow to pink was considered positive; rest of the 2 specimens were sent in formalin containers to Pathology Department and histopathological examinations were done. The presence of the gram-negative eosin stained bacilli was considered positive. Either the RUT biochemical test or the HPE test was considered positive for H. pylori. Histopathological examination with Giemsa gives information about the density of $\mathrm{H}$. pylori and the severity of gastritis. Sensitivity is $90 \%$ with Starry-Warthin stain, which is the most appropriate stain for the diagnosis of H. pylori. In Giemsa staining, sensitivity was proven to be $75 \%$ - 90\%.(9)

Alcoholics and their severity was assessed by DSMquestionnaire. The severity of alcoholism was graded using National Institute of Alcohol and Addiction (NIAAA) questionnaire. According to NIAAA (National Institute on Alcohol Abuse and Addiction), Alcoholic is a person who suffers from alcoholism. Alcoholism is also known as alcohol use disorder. It is marked by excessive and usually compulsive drinking of alcohol leading to psychological and physical dependence.(10) Volume of alcohol is defined as a drink in terms of grams ( $\mathrm{g}$ ). The alcohol content in strong Beer is $4.5 \%$, Light beer is lesser than $3.2 \%$ and Wine $12.9 \%$. Combination with varying mixtures have $15 \%$ to $40 \%$ of alcohol strength.

Spirits have high alcohol content (41.1\%) which include Gin, rum, vodka, whisky, scotch, bourbon and premixed cocktail. In India and East Asian countries there are many native preparations like arak, grain alcohol, malt alcohol, toddy. All drinks with $40 \%-60 \%$ alcohol have been included in the Arak group.

The study was conducted at MGMCRI, Pondicherry from June 2014 to May 2017 after approval by Human Ethics Committee.

\section{Exclusion Criteria}

1. Patient with structural disease.

2. Gall bladder disease

3. Serology positive (HIV, Hepatitis B, C).

4. H/o recent intake of NSAID or acid suppressing drugs.

Data was analysed using SPSS software. Descriptive statistics was calculated for background characteristics of study participants. Chi square test was done to determine statistical significance between proportions.

\section{Methodology}

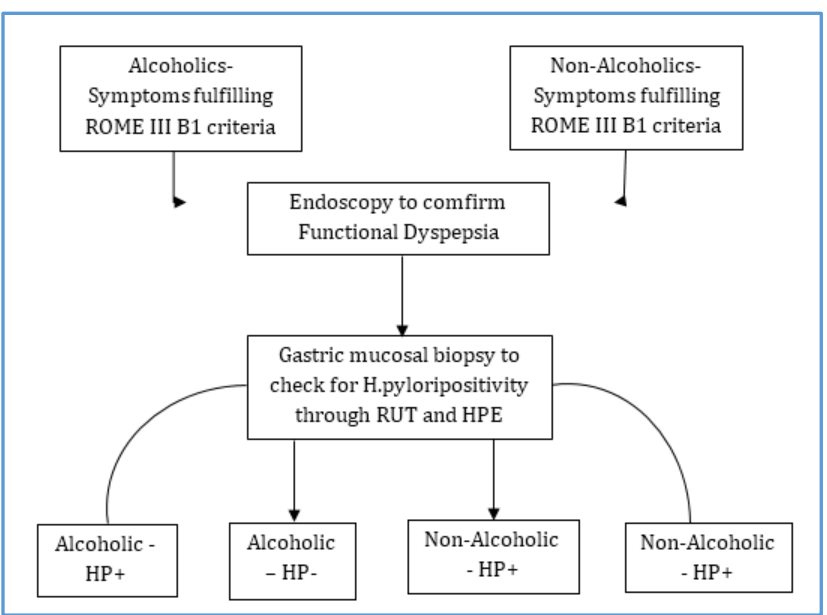

Histopathology of Gastric Mucosa/H. pylori seen as Pink Rods

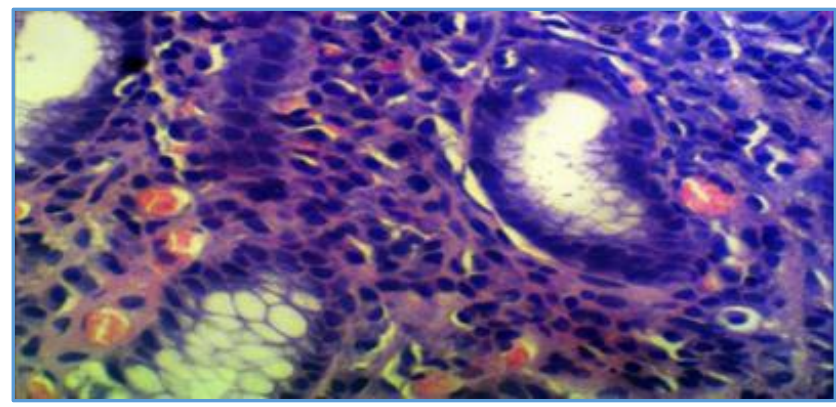

\section{RESULTS}

The study results are from 70 functional dyspepsia patients and of them 35 were alcoholics and 35 were non-alcoholics. Mean age of the study participants is 30 and age ranged from 18 to 70 . Mean duration of alcohol intake was $51 / 2$.

Figure 1 : Distribution of respondents based on type of alcohol consumed

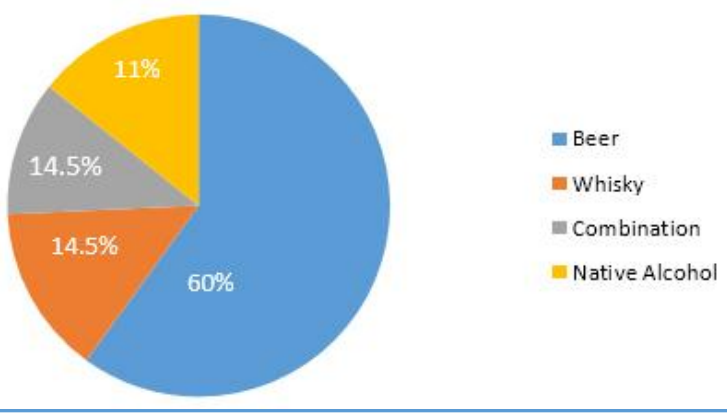

Of the alcoholics, people who consumed beer were more (60\%). Native alcohol consumers were fewer in our study and they consumed arak.

\begin{tabular}{|c|c|c|c|c|}
\hline \multirow{2}{*}{$\begin{array}{c}\text { Study } \\
\text { Groups }\end{array}$} & \multicolumn{3}{|c|}{ H. pylori } & \multirow{2}{*}{ P value } \\
\cline { 2 - 4 } & Positive & Negative & Total & \\
\hline Alcoholic (test) & $10(29 \%)$ & $25(71 \%)$ & 35 & \\
\hline $\begin{array}{c}\text { Non-Alcoholic } \\
\text { (Control) }\end{array}$ & $29(83 \%)$ & $6(17 \%)$ & 35 & $.000^{*}$ \\
\hline Table 1. H. pylori Prevalence in Alcoholics and Non- \\
Alcoholics
\end{tabular}

${ }^{*} \mathrm{P}$ value $<0.05$ indicates the difference is statistically significant.

The prevalence of H. pylori in FD cases was significantly higher in non-alcoholics (82\%) compared to alcoholics (28\%) and this difference was statistically significant ( $\mathrm{p}$ value < 0.05) (Table I).

\begin{tabular}{|c|c|c|c|c|}
\hline $\begin{array}{c}\text { Grams of } \\
\text { Alcohol } \\
\begin{array}{c}\text { Consumed/ } \\
\text { Day }\end{array}\end{array}$ & Positive & Negative & Total & \multirow{2}{*}{ P value } \\
\cline { 2 - 4 } & & & & \\
\hline Non-alcoholics & $29(83 \%)$ & $6(17 \%)$ & 35 & \\
\hline 30 to 90 & $3(13 \%)$ & $20(87 \%)$ & 23 & \multirow{2}{*}{$0.000^{*}$} \\
\hline 91 to 160 & $7(58 \%)$ & $5(42 \%)$ & 12 & \\
\hline \multicolumn{7}{|c|}{$39(56 \%)$} & $31(44 \%)$ & 70 & \\
\hline \multicolumn{7}{|c|}{ Table 2. Association between H. pylori Prevalence and } \\
Quantity of Alcohol Consumed \\
\hline
\end{tabular}

${ }^{*} \mathrm{P}$ value $<0.05$ indicates the difference is statistically significant. 
On comparing the quantity of alcohol consumed, H. pylori was more prevalent (58\%) in people who consume 91 to 160 gms of alcohol. This is higher in comparison with people who consume less alcohol in the range of 31 to 90 gms (13\%). This difference is statistically significant $(p<0.001)$, (Table II).

\begin{tabular}{|c|c|c|c|c|}
\hline $\begin{array}{c}\text { Duration of } \\
\text { Alcohol Intake }\end{array}$ & \multicolumn{3}{|c|}{ H. pylori } & \multirow{2}{*}{ P value } \\
\cline { 2 - 4 } & Positive & Negative & Total & \\
\hline Non-Alcoholic & $29(83 \%)$ & $6(17 \%)$ & 35 & \\
\hline 4 to 12 months & $1(8 \%)$ & $11(92 \%)$ & 12 & \multirow{2}{*}{$0.000^{*}$} \\
\hline $\begin{array}{c}13 \text { to } 120 \\
\text { months }\end{array}$ & $6(40 \%)$ & $9(60 \%)$ & 15 & \\
\cline { 1 - 4 } $\begin{array}{c}121 \text { to } 240 \\
\text { months }\end{array}$ & $3(38 \%)$ & $5(62 \%)$ & 8 & \\
\hline Total & $39(56 \%)$ & $31(44 \%)$ & 70 & \\
\cline { 1 - 3 } $\begin{array}{c}\text { Table 3. Association between Prevalence of H. pylori and } \\
\text { Duration of Alcohol Consumption }\end{array}$ \\
\hline
\end{tabular}

${ }^{*} \mathrm{P}$ value $<0.05$ indicates the difference is statistically significant.

On comparing the duration of alcohol consumed, H. pylori was more prevalent (40\%) in people who consumed 13 - 120 months duration. This is higher in comparison with people who consume alcohol for lesser duration, 4 to 12 months $(8 \%)$. This difference is statistically significant $(\mathrm{p}<0.001)$, (Table III).

\section{DISCUSSION}

This study showed that the prevalence of H. pylori was higher in non-alcoholic than in moderate drinkers on a regular basis and high in binge drinkers, which is statistically significant. The reason for this prevalence of $\mathrm{H}$. pylori is low in moderate drinking and high in severe drinking can be explained as follows.

\section{The Reason for Low Prevalence in Moderate Drinking} are-

1. Antibacterial effect of alcohol, which shows a direct cytotoxic effect or sterilisation effect on the H. pylori.11

2. Unfavourable $\mathrm{P}_{\mathrm{H}}$ produced by alcohol in the gastric mucosa, which is a lethal acidity. ${ }^{12}$

3. Chronic active gastritis attracting the white blood cells whose inflammatory mediators, cytokines and the interleukins which eliminate the bacilli. ${ }^{13}$

The Increased Prevalence in Severe Alcoholics is explained as follows-

1. Increased alcohol concentration disrupts the mucosal barrier and increases the mucosal permeability to the organism. ${ }^{14}$

2. This in turn leads to decrease in prostaglandin production, which increases the local damage inflammations and population of $\mathrm{H}$. pylori.

3. Increasing age of the patient and increase in the quantity of intake reduces the immune-mechanisms of the host, so the H. pylori prevalence is more. 15

4. From the bacterial aspect, the Bab-A or bacterial adherence factors namely sialic and adhesion (Inflammatory protein- $\mathrm{Hp} \mathrm{0638)} \mathrm{lead} \mathrm{to} \mathrm{positive}$ virulence. This happens in heavy drinkers or binge drinking habits. ${ }^{16}$
5. So the conclusion is that alcoholism shows an inverse $U$ shaped relationship with $\mathrm{H}$. pylori prevalence ${ }^{17}$ among functional dyspepsia patients.

\section{Limitations of the study}

The sample size of 70 is too small and there was no definitive standard tool to measure the severity of alcohol addiction. Urea Breath test, IgG antibodies against $\mathrm{H}$. pylori and faecal antigen test should have been more comfortable for the patient and perhaps could yield better results. In alcoholics, even blood alcoholic level (BAL) was widely variable and not a reliable tool to assess the severity of symptomatology or behaviour. Most of the deserving FD patients who refused endoscopy had to be excluded from the study. Most of the patients were widely self-medicated with PPI and the exact $H$. pylori prevalence was influenced by that.

\section{CONCLUSION}

The causative agents for FD, the definitive relationship of alcohol and $\mathrm{H}$. pylori are unsolved enigma and lots of avenue is there for further research. People should not have misconception that alcohol has a beneficial antioxidant effect on gastric mucosa protecting it against dyspepsia and ulceration.

\section{REFERENCES}

[1] Mahadeva S, Goh KL. Epidemiology of functional dyspepsia: a global perspective. World journal of gastroenterology 2006;12(17):2661-6.

[2] Ghoshal UC, Singh R. Functional dyspepsia: the Indian scenario. J Neurogastroenterol Motil 2012;60:6-8.

[3] Vakil N, Moyyedi P, Fennerty MR, et al. Limited value of alarm features in the diagnosis of upper gastrointestinal malignancy systematic review and meta-analysis. Gastroenterology 2006;131(2): 390-401.

[4] Track J, Talley NJ, Camilleri M, et al. Functional gastroduodenal disorders. Gastroenterology 2006;130(5):1466-79.

[5] Talley NJ, Choung RS. Whither dyspepsia? A historical perspective of functional dyspepsia, and concepts of pathogenesis and therapy in 2009. J Gastroenterol Hepatol 2009;24(Suppl 3):S20-8.

[6] Marshall B. Helicobacter pylori: 20 years on. Clin Med 2002;2(2):147-52.

[7] Smoak BL, Kelley PW, Taylor DN. Seroprevalence of helicobacter pylori infections in a cohort of US army recruits. Am J epidemiol 1994;139(5):513-9.

[8] Wang A, Liao X, Xiong L, et al. The clinical overlap between functional dyspepsia and irritable bowel syndrome based on Rome III criteria. BMC Gastroenterol 2005;8:43.

[9] Dufour MC. What is moderate drinking? Defining drinks and drinking levels. Alcohol research and health 1999;23(1):5-14.

[10] Jones VS, Kate V, Ananthakrishnan N, et al. Standardization of urease test for detection of helicobacter pylori. Indian J Med Microbiol 1997;15(4):181-3. 
[11] Kumar GS, Premarajan KC, Subitha L, et al. Prevalence and pattern of alcohol consumption using alcohol use disorders identification test (AUDIT) in rural Tamil Nadu, India. Journal of clinical and diagnostic research 2013;7(8):1637-9.

[12] Talley NJ, Zinsmeister AR, Schleck CD, et al. Smoking, alcohol and analgesics in dyspepsia and among dyspepsia subgroups: lack of association in a community. Gut 1994;35(5):619-24.

[13] Halder SL, Locke GR Ill, Schleak CD, et al. Influence of alcohol consumption on IBS and dyspepsia. Neurogastroenterol Motil 2006;18(11):1001-8.

[14] Brenner H, Bode G, Adler G, et al. Alcohol as gastric disinfectant? The complex relationship between alcohol consumption and current helicobacter pylori infection. Epidemiology 2001;12(2):209-14.
[15] Gikas A, Triantafillidis JK, Apostolidis N, et al. Relationship of smoking and coffee and alcohol consumption with seroconversion to helicobacter pylori: a longitudinal study in hospital workers. J Gastroenterol Hepatol 2004;19(8):927-33.

[16] Kuepper - Nybelen J, Thefeld W, Rothenbacher D, et al. Patterns of alcohol consumption and helicobacter pylori infection: results of a population-based study from Germany among 6545 adults. Aliment pharmacol Ther 2005;21(1):57-64.

[17] Ogihara A, Kikuchi S, Hasegawa A, et al. Relationship between helicobacter pylori infection and smoking and drinking habits. Journal of gastroenterology and Hepatology 2000;15(3):271-6. 